\title{
Dr. Pliny Earle on Blood-letting in Insanity.
}

To the Editor of the Asylum Journal of Mental Science.

\section{Dear Sir,}

The issue of your Journal for January last, contains a review of "An examination of the practice of blood-letting in mental disorders," which appears to call for some explanation from me. In regard to the general tenour of that review, I shall not raise a single objection. The book is before the public, and reviewers have an unquestioned right to express their opinions of it; at the same time they will concede to me the right of reply.

The only really important issue between the reviewer and me, is this:-Is the general plan of the "Examination" that which, in the present state of the science of mental pathology, and the art of treating mental disorders, is the best adapted to the wants of the medical profession? He would have "the question of blood-letting in insanity thoroughly handled ;" he thinks that "an examination of the action, and the indications of blood-letting, by the aid of our improved pathology, and by the teachings of experience; a collection of statistics and of cases illustrative of its good or evil effects in the course and in the cure of mental disorders, would have formed a highly instructive and useful book;" yet the "Examination" is "unsatisfactory" to him. That essay includes all the statistics upon the subject, which were in my possession; I know of no others. It contains the opinions of all the best authorities upon the "action," or the effects, of blood-letting. It is there shewn, that Drs. Ray, Underwood, White, Macdonald, S. H. Smith, Sutherland, Seymore, Ellis, Esquirol, Dubrisson, Zeller, and others, believe that bleeding causes "dementia," "fatuity," or "idiocy." The inference is, that their belief is founded upon observation, of both therapeutical action and pathology in practice. Why should I demand statistics from them to prove that their belief is a logical sequence of that observation? The expressed opinions of such men require no confirmatory evidence. It is there shewn that Drs. Woodward, White, Patterson, Allen, Burrows, Jacobi, and others, believe that bleeding causes "debility," "prostration," "exhaus، tion." Wherefore ask for their theories in regard to the manner in which these effects are produced? Were those theorics given they might be very diverse; some of them might coincide with mine, and some might not: and who 
could decide upon the right? It is shewn, that Drs. Wyman, Brigham, S. H. Smith, Sutherland, Ellis, Millingen, and others, believe that it causes death. If such be its effeets, why endeavour to ascertain in what particular functional manner that result is brought about, when I know, that with our present knowledge of pathology, no man can positively demonstrate it? I may believe that the debility, and the fatuity, are the sequences of a prostration of nervous power by the abstraction from the brain of the material which, in some way, assists in the generation of that power. Others may entertain a different opinion; who shall act as umpire between us? It is there shewn, that Dr. Bucknill never resorts to general blood-letting. It is to be presumed that he has good and sufficient reasons, not only for the faith that is in him, but for the practice which he pursues. It is shewn, that Dr. Monro and Sir Alexander Morison never resort to it "except in cases of apoplexy and phrenitis;" they undoubtedly thus abstain because observation has taught them that it is the safe and better course, and not in obedience to preconceived hypothesis. It is shewn, that Dr. Conolly "is convinced that great blood-letting is rarely admissible, and generally dangerous in insanity." What produced that conviction, theory or practice? And if such be his conviction is not his opinion of just as much practical value as if he had attempted, (an attempt which must have proved futile,) to shew the exact molecular method by which venesection acts, all the way from the cut of the lancet to the last throb at the centre of life !

Hitherto we have discovered no Ariadne's thread by which to be guided, especially in the path of pathology, through the labyrinth of the brain to the seat and source of nervous power, which in my view, is the seat and source of vitality. The scalpel has opened but to the alphabet of the sealed and mysterious book. Pathological appearances have sometimes deceived, sometimes puzzled and bewildered us; they have yielded but a particle of positive knowledge which is available in practice. Neither chemistry nor the microscope has revealed the important secret which we all desire to know. Of the manner of the brain function, of the precise degree of necessity, and the reason for that necessity, of the blood, in the aperations of the brain; of the ultimate method by which modifications of the brain function are produced by the vital fluid, by disease, or by therapeutical agents, our knowledge is so limited as to avail but little in the determination of our mode of practice. 
Hence the medical treatment of insanity is almost purely empirical. The present prevailing practice was commenced in this country, by men who closely observed therapeutical effects and rarely made microscopical investigations. Practically, here, therapeutics has forced us to a more nearly correct theory of pathology. Pathology has governed our therapeutics only by sustaining it, when viewed in the light which the latter had already thrown upon the former.

Thus much has been written to shew the grounds of my belief, that, at the present day, the opinions upon therapeutic effects of the men who are, or recently have been, engaged in the treatment of the insane, are in effect, the highest and best exponents of our knowledge of the pathology of mental disorders, and the safest and best guide in practice. If, in the "Examination," I have quoted some comparatively ancient authors, it was not from any belief of mine in the doctrines which they taught, but because there are other men who still retain their faith in them.

These views of the subject induced me, in an attempt to ascertain the true nature of blood-letting in mental disorders, to adopt the plan which was pursued in the "Examination." I tnought that the evidence adduced in that essay is of more value than the theory of any individual, even that of the most profound pathologist, or the inductions derived from any statistics which could then be collected.

Now, if the "Examination" does not meet the wishes and views of my reviewer, as expressed in the foregoing quotations from his review, I can imagine nothing which will meet them, until some genius shall have arisen and performed for mental pathology, that which Copernicus, Kepler, and Newton performed for astronomy. If I rightly understand him in these and other parts of the review, he would not be satisfied with anything short of a positive, unquestionable demonstration of the proximate, mediate, and ultimate molecular action of blood-letting in the production of good or ill effects upon the system of the insane patient; and an exposition of the indications for it, so clear, so definite, so unsusceptible of modification by the condition of the age, sex, temperament, habit, season, and climate, that the reader might unhesitatingly adopt it as an invariable rule of practice. If this be true, he wants an impossibility.

There were other circumstances which influenced my decision upon the plan of the "Examination." It is not the fact, that in this country, Dr. Rush "is almost without a follower," and that his "theories and arguments have lost their force 
and authority." Over a vast extent of our inland territory, the treatment recommended by him is still to a very considerable extent in vogue; and the professor of the practice of medicine in our largest medical school, inculcates that method of treatment, and its supporting theories. When the physicians connected with the institutions for the insane have denounced venesection, they have been confronted by what was considered the paramount authority of Dr. Rush; they have then been told, "You asylum gentlemen," or sometimes, "You crazy doctors, ride hobbies;" as if he who makes insanity a speciality, may not be as well qualified to speak of his department of the profession, as is the surgeon or the obstetrician to speak of that department to which he is devoted: and as if Dr. Rush were not as liable to hobby-riding, as Dr. Ray, or Dr. Bell, or Dr. Kirkbride. Now, what individual authority could overcome the far-prevailing, but happily, not as formerly the all-pervading influence, of the opinions of Dr. Rush? not that of any man within or without the States. It was therefore deemed best to shew, that if asylum gentlemen $d o$ ride hobbies, they are remarkably gregarious; and that the doctrines of Rush are opposed, not by one, nor by two alone, of the modern physicians of the insane, but by every one who has written upon the subject in this country; and by nearly all the Europeans whose opinions have been published. It will be perceived from the preceding remarks that the "Examination" was written specially for the latitude and longitude of the United States. If the convictions and circumstances which would modify its adaptability to the wants of the profession, are different in England from what they are here, it necessarily follows, that if it be judged by the standard of those conditions and eircumstances, it must be judged unfairly. Be that as it may, a man whose opinion, in all matters relating to insanity, I esteem as second to that of no other in the world, has, unrequested, asserted that the "Examination" is precisely what was needed; and another, whose experience, position, and reputation for sound judgment, place him in the foremost rank of American psychologists, has said, although his opinion was also unasked for, "That it will save the lives of hundreds." With these decisions upon the merits of the book, I surely ought to be, as I am, well satisfied.

It is here proper to say in justice to the deceased author, as well as to myself, that $I$ hold in very high estimation the general character of Dr. Rush. My medical education was received at the school in which he had formerly been a provoL. II. NO. 20 . 
fessor; and with the respect, the esteem, and the affection for the professors at whose feet I sat, I imbibed the sentiments of reverence for Dr. Rush. I respect him as a man highly gifted with intellectual powers. I admire him in his character as a labourer, active, industrious, earnest, and long persevering in the field of science. I place a still more exalted estimate upon him as a kind, a sympathetic, a benevolent physician. In common with his other countrymen, I greatly honor him as a patriot kind and true, who stood firmly by his country, throughout the day of her greatest peril and her sorest need; and deliberately threw his life into the delicately poised balance, by subscribing his name to the declaration of the fourth of July, 1776. It is only to his theories of the pathology, and his principles of the therapeutics of insanity, and the inconsistencies into which he was led in support of them, that I have objected. These alone, have I attacked. Had those theories and principles died with their originator, I would have been among the first, with no misgivings, to place the laurel-wreath upon his grave. But, as has been shewn, they still live in America; and if they do not in England, why has Dr. Henry Monro written (in the Asylum Journal for April, 1856) as follows? "The term Mania has become inveterately associated among practitioners of the old school, (many of whom still exist,) with a strength to be pulled down; a disease requiring antiphlogistic treatment."

Such a practitioner sees a man raving mad; he says, "Here is excess of nervous action." This must indicate excess of vigour, and this requires a depleting treatment; he bleeds, he blisters, and purges, and finds the fury mitigate for a time; and says, again, "Mania must be the result of an excess of power." If then, I conscientiously believe that certain theories and principles are annually consigning hundreds prematurely to the grave, and hundreds more to permanent insanity; and if I know that the book which inculcates those theories and principles is still extant, and probably to be found in more libraries than all other books upon the same subject; shall I refrain from an endeavour to expose the errors of those theories and principles, simply because the author of that book is not living? Shall thousands be sacrificed to respect for the memory of one? Who will answer these questions in the affirmative? If Dr. Rush's doctrines of insanity be correct, let those who believe so, come forward and vindicate them? If his arguments in support of them, be logical, let his followers make clear that logic, and prove that $\mathbf{I}$ am in error? But even the reviewer, although he 
quotes my exposition of that logic, to show how Dr. Rush's opinions are "belabored," does not even insinuate that I have misrepresented the text.

Respectfully yours,

Leicester, Massachusetts,

PLINY EARLE.

November 14, 1856.

The Military Lunatic Hospital; a Summary of the Minutes of Evidence taken before the Select Committee on the Medical Department (Army) so far as they relate to the re-establishment of that Hospital. By C. Lockhart Robertson, M.B. Cantab., \&c., \&c., \&c.

At the last annual meeting of the association at the Derby County Asylum, on the 1st of August, I had the honour of moving the following resolutions relative to the military lunatic asylum, based on the report of Mr. Stafford's select parliamentary committee which had just before been printed by order of the House :

1. That this Association view with unqualified satisfaction the recommendation contained in the 16 th section of the report of the Select Committee of the House of Commons, appointed on the medical department of the army, and that a Military Lunatic Asylum be provided as embraced in the design for the new Military Hospital at Southampton.

2. That this Association desire respectfully to convey to the Right Honourable the Minister of War and to the Director General of the Army Medical Department, the satisfaction it will afford the members of the association to place their practical experience in the arrangements of such institutions, at the disposal of those to whom the fitting up and charge of the new Military Lunatic Hospital may be entrusted.

3. That a copy of these two resolutions be forwarded to the Minister of War and to the Director General of the Army Medical Department.*

* In the following letters the Director General and the Right Hon. the Secretary of State for War thus courteously acknowledge the receipt of these resolutions:

6, Whitehall Yard, Westminster, Oct. 17th, 1856.

1. Sir,-In acknowledging the receipt of your letter of the 16th inst., I have to inform you that it has afforded me much gratification to find that the 